\title{
'||||||||||||||||||||||||||||||||||||||||||||||||||||||||||||||||||||.
}

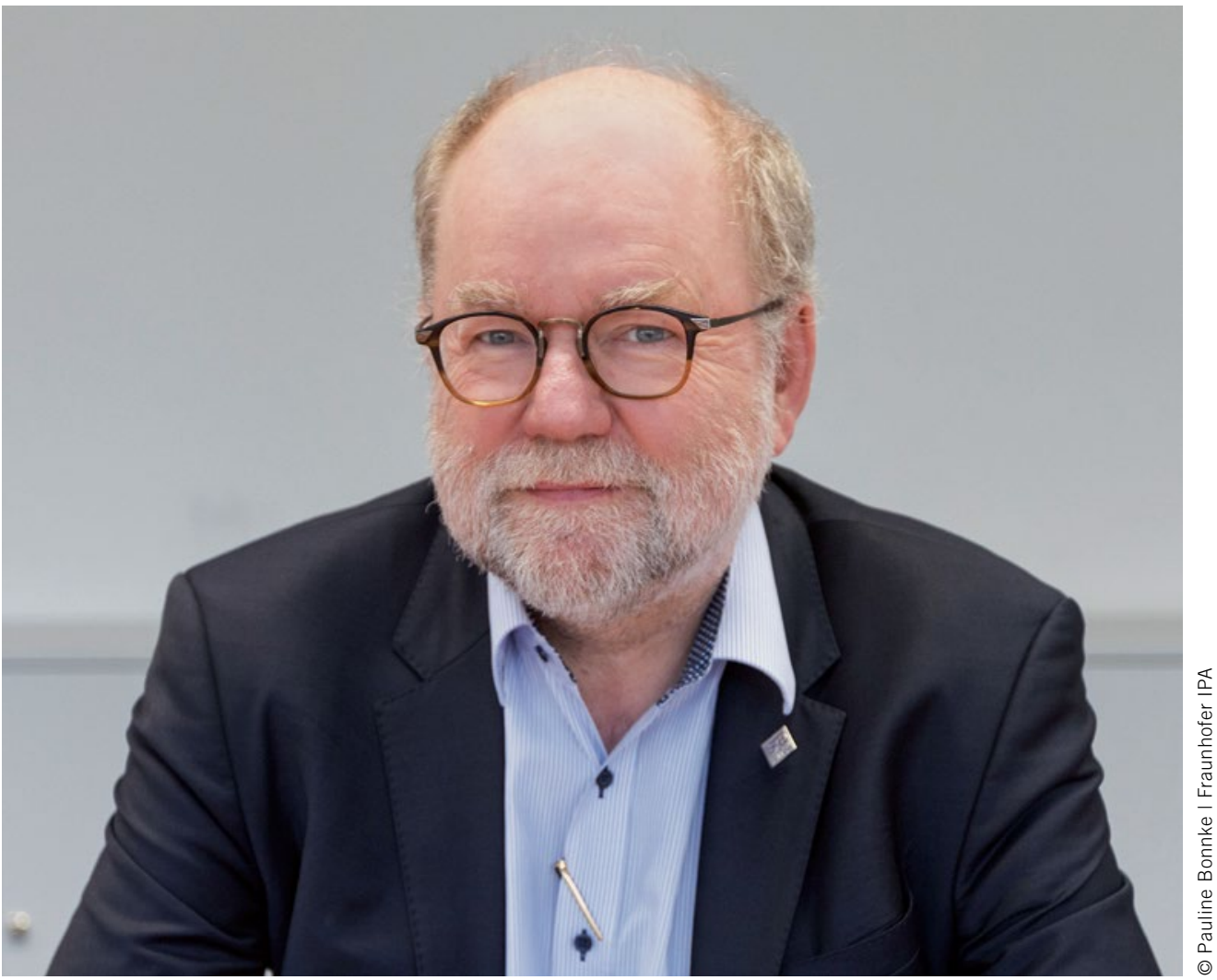

Prof. Michael Bargende Chair of Automotive Powertrains at the Institute Automotive Engineering Stuttgart of the University of Stuttgart

\section{Nothing Will Be Quickly the Same Again ...}

I very much hope that by the time you are reading this we are back on the road to normality again and we have put the corona crisis at least a little way behind us. I also trust that we will have escaped relatively lightly. However, I fear that it will be much more difficult and take much longer for the economy to recover than was the case after the global economic crisis of 2009.

When the pandemic is over, we will once again start focusing on climate change and on reducing $\mathrm{CO}_{2}$ emissions. During the corona crisis, the $\mathrm{CO}_{2}$ emissions from transport are falling significantly, but they will start to rise as things return to normal. People will once again use their cars to commute to work, go on business trips and travel on vacation. What will be different? Many people will have less money available and this will bring two consequences. On the one hand, they will keep hold of their cars for longer and buy fewer new models. On the other, when they do buy a new car, their main focus will be on the price. My prediction is that this will not be a good time for introducing electric vehicles. But how will we achieve the ambitious reduction targets set by working group 1 of the National Platform Future of Mobility by 2030 ?
In my view, there is only one socially responsible solution. We need to reduce the $\mathrm{CO}_{2}$ emissions from our existing vehicle fleet and the only way to do this is with synthetic fuels. We have never needed them quite as much as we do now. Our policymakers should put in place an honest and realistic strategy for avoiding the production of $\mathrm{CO}_{2}$ and acknowledge that synthetic fuels are an important means of reducing emissions from transport. This would create the security that investors need to put their money into the construction of production plants.

Otherwise we will once again fail to meet our $\mathrm{CO}_{2}$ targets and sales of fossil fuels in gas stations will continue to rise. But by then it will be too late, because it will take years to produce enough synthetic fuels to achieve a noticeable effect. It would be ideal if the production facilities were located in countries where the sun almost always shines. Then the efficiency level of these fuels in our engines would be almost the same as if they were converted back into electricity and used to power electric vehicles. If you take the environmental impact of manufacturing large batteries into the equation, I don't need to tell you which type of powertrain has a better carbon footprint for long-distance transport. 